\title{
Lower mortality is observed among low birth weight young infants who have received home-based care by female community health volunteers in rural Nepal
}

Dinesh Neupane ${ }^{1,2,3^{*}} \mathbb{D}$, Penny Dawson ${ }^{2}$, Robin Houston ${ }^{2}$, Liladhar Dhakal ${ }^{2}$, Jaganath Sharma ${ }^{2}$, KC Gargi $^{2}$, Christina Lagos², Vishnu Khanal ${ }^{3}$, Shiva Raj Mishra ${ }^{3}$ and Per Kallestrup ${ }^{1}$

\begin{abstract}
Background: There has been little success in attempts to reduce the proportion of births with low birth weight (LBW). However, deaths associated with LBW may be prevented with extra attention to warmth, feeding, and prevention or early treatment of infections. There are few studies on this in Nepal and in many other developing countries. This is a cohort study to evaluate the risk of deaths among LBW infants who received FCHV follow up visit for home-based care compared to those who did not receive in Rural Nepal.

Methods: A cohort study design was used with data from the Morang Innovative Neonatal Intervention (MINI) program in Nepal. Relative Risk (RR) is calculated to compare LBW neonates who received FCHV follow up visit as compared to LBW neonates who did not receive visit.

Results: Out of 51,853 newborn infants recorded in the MINI database, 2229 LBW neonates were included in the analysis. The proportion of deaths among those who received FCHV follow up visit and those who did not receive were $2 \%(95 \% \mathrm{Cl}: 1 \% ; 2 \%)$ and $11 \%(95 \% \mathrm{Cl}: 6 \% ; 18 \%)$ respectively $(P<0.001)$. The relative risk of death in LBW infants who received FCHV follow up visit was $84 \%$ less as compared to LBW infants who did not receive $(\mathrm{RR}=0.16 ; 95 \% \mathrm{Cl}: 0.09,0.29)$.
\end{abstract}

Conclusion: The current study indicates that to save the lives of LBW young infants simple home-based measures implemented through trained health volunteers within the existing government health system may be effective when technically more sophisticated measures such as tertiary health centers, pediatricians, and expensive technology are limited.

Keywords: Low birth weight, Community health workers, Newborn, Nepal

\section{Background}

Low Birth Weight (LBW) is defined by the World Health Organization (WHO) as weight at birth of less than $2500 \mathrm{~g}$ [1]. LBW which is caused by preterm birth or intrauterine growth retardation, constitutes only about $15 \%$ of children born, but accounts for $60-80 \%$ of neonatal deaths $[2,3]$. The highest incidence is observed

\footnotetext{
* Correspondence: neupane.dinesh@gmail.com

${ }^{1}$ Center for Global Health, Department of Public Health, Aarhus University, Aarhus, Denmark

${ }^{2}$ JSI Research and Training Institute Inc, Kathmandu, Nepal

Full list of author information is available at the end of the article
}

in South Asia, where an estimated $31 \%$ of neonates are born LBW, making up nearly half of the world's LBW neonates [4]. The fourth Millennium Development Goal (MDG-4) commits the international community to reducing mortality in children less than five years of age by two-thirds between 1990 and 2015 [5]. The Nepal Demographic and Health Survey showed there was a minimal reduction in the proportion of LBW infants from $14 \%$ in 2006 to $12 \%$ in 2011 [6, 7]. As the majority of births occur at home [6], it is difficult to identify LBW births occurring in Nepal's rural communities and to intervene and manage the consequences of LBW. 
Therefore, community based management of LBW is essential in order to achieve Sustainable Development Goal-3 related to child health.

There has been little success in the attempts to reduce the proportion of LBW births [8]. However, deaths from LBW can be prevented with extra attention to warmth, feeding, and prevention or early treatment of infections [9-11]. Over a period of eight years, a study in India showed that there was a $58 \%$ decline in case fatalities among LBW neonates who received these preventive measures [12]. An earlier study in Pune, India revealed that home-based management of neonates with LBW or preterm birth, babies with asphyxia, feeding problems or illness achieved a $25 \%$ reduction in neonatal mortality by providing advice on keeping the baby warm, exclusive breast-feeding and minimum handling of the baby [13].

Despite the importance of the adverse impact of LBW on child survival, there have been few prospective studies evaluating effectiveness of community based intervention through trained volunteers for LBW infants in Nepal and in other developing countries, largely because of the difficulties inherent in community based data collection and the higher proportion of births occurring at home [12] [13]. As a result, there is inadequate information about effectiveness of community based intervention preventing deaths among LBW infants from such settings. This has hindered the development of appropriate neonatal interventions in the developing countries, especially within existing government health programs. This study explores the impact of community based management of LBW infants on mortality within two months of age, by mobilizing Female Community Health Volunteers (FCHVs) from the Morang Innovative Neonatal Intervention (MINI) program, a prospective cohort study from Nepal. Infants 0 to 2 months were included in the study because Nepal's IMCI guidelines at the beginning of the project (2005) only addressed illnesses in children from 2 months to 59 months [14].

FCHVs are local women with limited formal education, who are serving voluntarily within the government system. They receive basic training (18 days) and periodic refresher and program-specific training. Approximately 50,000 FCHVs work actively in all villages of Nepal and are supported by Facility-Based Community Health Workers [15]. Their coverage extends up to wards-the smallest subdivision in villages and municipalities of Nepal. In the MINI program, FCHVs were provided with five days training on the management of neonatal sepsis. Serving a ward ranging from 1000 to 3000 in population, each FCHV was in direct contact with expecting mothers. FCHVs resupplied iron and folic acid tablets to pregnant women, encouraged them to attend antenatal care at health facilities, and provided counseling on essential newborn care messages and danger signs for possible severe bacterial infections (PSBI) in young infants (less than two months). In addition, independent of MINI's program model, FCHVs conducted monthly mothers' group meetings in their communities to raise awareness on a broad range of health topics and to introduce any new programs.

\section{Methods}

\section{Study setting}

Nepal is a low-income country of 26.5 million inhabitants, $78 \%$ of which live on less than two dollars a day and $83 \%$ of which live in rural and often remote areas $[16,17]$. Its diverse ecological regions and unstable political situation create challenges for systematizing healthcare delivery [18]. In Nepal, on average only $50 \%$ of pregnant mothers attend the recommended four antenatal care visits at health facilities, and only $45 \%$ of mothers attend postnatal care, and this failure to appear is a risk factor for negative pregnancy outcomes, including LBW newborns [6].

Morang Innovative Neonatal Intervention (MINI) program focused on community based management and treatment of illnesses of newborn children in the Morang district of southeastern Nepal from 2005 to 2009 [19]. Morang is the second most populous district of Nepal, after Kathmandu, yet $80 \%$ of the total population of 914,799 live in rural areas. The per capita yearly income for Morang was USD 297 and the overall literacy rate was reported as $56 \%$ (female $47 \%$ and male $67 \%$ ) $[20,21]$. Morang district has 65 Village Development Committees (VDCs), two hospitals, seven primary health care centers, ten health posts, and 49 sub-health posts. There were 585 FCHVs in the District at the time of the study.

\section{Study design}

MINI was a prospective intervention study aimed at managing newborn's illnesses at household and community level. MINI began in 21 randomly selected VDCs in Morang, but due to initial successes and demand from local government from the VDC level and the District Public Health Office (DPHO) level, it was rapidly scaledup to the entire Morang district covering all 65 VDCs. This is a cohort study utilizing the data from the MINI program to evaluate the risk of deaths in LBW infants who received follow up FCHV visit or not.

FCHVs were trained to measure birth weight on their initial visit and to do follow-up visits to advise on care of LBW babies. The choice to do a follow-up visit was voluntary and they did not receive any incentive for doing such follow-up visits. During the first visit, FCHVs recorded date of birth, birth place, birth condition, weight and assessed for any infection, as well as providing counseling on essential newborn care. For LBW 
babies, they conducted four additional follow-up visits on a weekly basis. On each follow up visit, they reassessed the young infant for signs of Possible Severe Bacterial Infection (PSBI) [22, 23], advising mothers to seek care immediately if any of these signs appeared, and counseling the mother on exclusive and frequent breastfeeding and skin-to-skin contact. FCHVs used topical antibiotics for Local Bacterial Infection (LBI- eye and skin infection) and initiated treatment with oral Cotrimoxazole-P and referred to facility-based health workers for Gentamicin injections for PSBI [14, 24]. FCHVs were already familiar with using Cotrimoxazole$P$ for treatment of pneumonia in older children and this antibiotic was successfully used in earlier study [24]. The infants referred for PSBI continued to get weekly follow up visits.

\section{Data collection}

During training of FCHVs in MINI, they were provided with Salter scales and trained to measure the weight of newborns. Given the varying levels of literacy among FCHVs (38\% of FCHVs in Nepal are illiterate) [15], MINI modified the Salter scale by coding weight ranges with colors to simplify measurements. The red, yellow and green portions of the scale signified Very Low Birth Weight (VLBW), LBW and normal birth weight respectively. Newborns weighing $<2000$ g were categorized VLBW (red color), those weighing between $2000 \mathrm{~g}-2500 \mathrm{~g}$ were categorized LBW (yellow), and those weighing $>2500 \mathrm{~g}$ were considered normal weight (green). If FCHVs circled the VLBW image in the birth weight section, they referred the infant and family to the nearest health facility. If the family did not comply with health facility referral, FCHVs visited the home, as they would for a LBW case, and marked the visit number on the recording form. Families with LBW babies were counseled further on newborn care. The FCHV then conducted four additional home visits (weekly for one month) for the LBW neonates.

Regardless of FCHVs follow up visits, the FCHV conducted a two-month (in 60 or more days) visit to determine the infant's survival status at 60th day. MINI's trained field supervisors collected and consolidated data from FCHVs on a regular basis. Standard forms and formats were developed and used for this purpose.

\section{Statistical analysis}

Any infants with birth weight measured three days after birth, weight not-taken or survival status not known at the two-month were excluded from the analysis in order to maintain data consistency. Similarly, for comparing infants who received no follow visit and those who received at least one follow up visit by the FCHV for LBW infants, neonatal deaths within one week of birth were excluded as these population were not able to receive intervention from FCHVs. Furthermore, those infant ( $n=97)$, who were referred and taken to health facility received advanced care from referral hospital, were excluded from analysis as including them would overestimate the effect of FCHVs visit. Ethnicity classification was done based on the Health Management Information System (HMIS) of the Government of Nepal, which categorizes ethnicity in six categories namely, (i) Dalits, (ii) Disadvantaged Janajatis, (iii) Disadvantaged Non-Dalit Terai Caste Groups, (iv) Religious Minorities, (v) Relatively Advantaged Janajatis, and (vi) Upper Caste Groups [25]. Chi-square test was used to identify statistical difference in mortality outcomes between FCHVvisited and not-visited LBW neonates. Relative risk was calculated after adjusting for birth place to measure the relative risk reduction of death among LBW neonates who received an $\mathrm{FCHV}$ follow up visit compared to those who did not. $P$-values $<0.05$ were considered statistically significant.

\section{Ethical considerations}

Informed oral consent of the infant's legal guardian was obtained. The Ministry of Health and Population, Nepal approved the intervention. Ethical approval to conduct this study was obtained from the Western Institutional Review Board (WIRB) (WIRB Pro No. 20031870).

\section{Results}

\section{Characteristic of samples}

The exclusion and inclusion criteria for this study are presented in Fig. 1. Out of 51,854 young infants recorded in the MINI database, 51,020 were live births, 716 were stillbirths and 118 did not have any information on birth condition. Among the live births, 11,075 did not have any information on birth weight and for 19,901 weights were measured after three days. Among 20,044 live births visited by FCHVs within three days, 17,462 had normal weight, 2103 had low birth weight, 327 had very low birth weight and 152 did not have any information on birth weight. From the low birth weight cohort, including very low birth weight, seven were lost to follow up, 97 were taken to a health facility after the referral by FCHV and 97 died within a week. The remaining 2229 births were included in the analysis.

The detailed characteristics of the young infants who were included in the analyses are presented in Table 1. Among 2229 low birth weight young infants, 53\% were female. Ethnically, the majority of the infants were Disadvantaged Janajati (40\%) followed by Disadvantaged Dalit (21\%). There were 49 (2\%) deaths between eight days and two months of age. The majority of births occurred at home (78\%). Two hundred and eighty-six young infants had PSBI, among them 177 were identified 


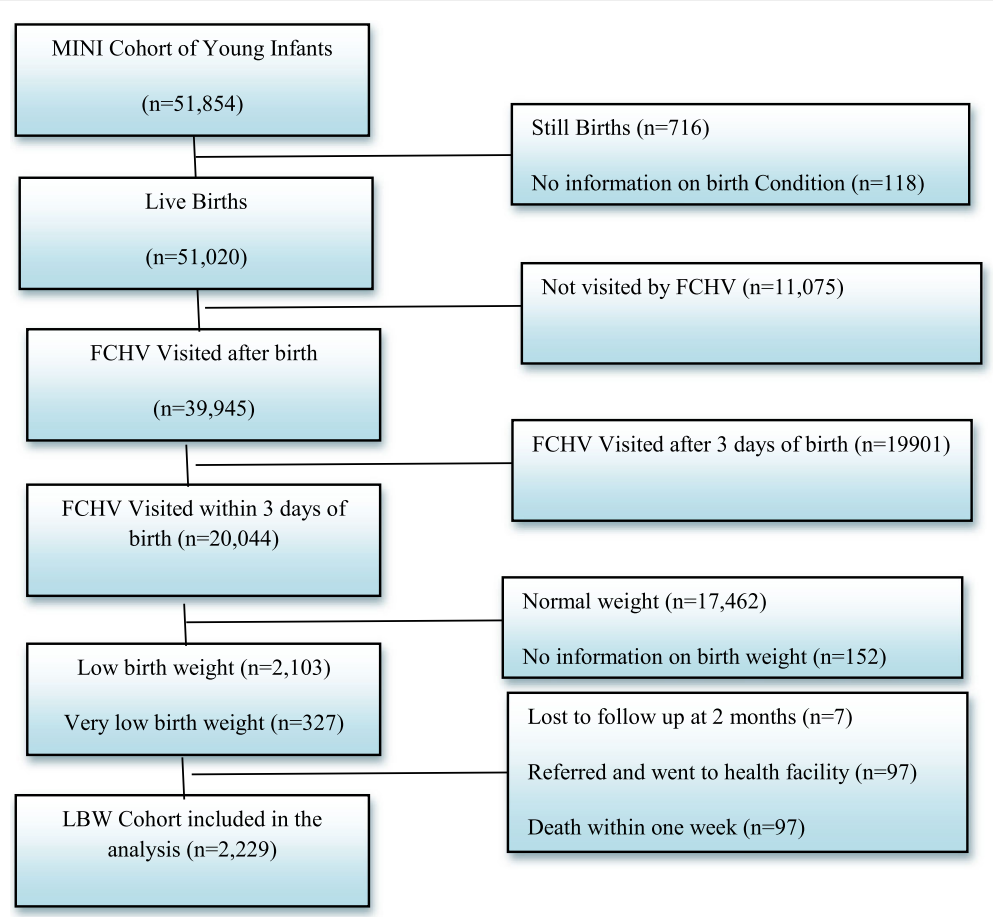

Fig. 1 The exclusion and inclusion criteria of the study

by FCHVs and initiated treatment with oral antibiotic and referred for injectable antibiotics. The remaining 109 PSBIs were diagnosed by the local health workers from the health facilities. Likewise, 464 young infants had LBI and were treated by FCHVs using topical antibiotics. Among the 2229 LBW infants, 121 (5.4\%) received no follow-up visits. No statistically significant differences between those with and without follow-up visits were observed by sex $(P=0.09)$, illness $(P=0.37)$, first place of treatment $(P=0.59)$ and ethnicity $(P=0.48)$. However, these two groups were s significantly different by birth-place $(p=0.03)$ (Table 1$)$.

Mortality status at 60th day in LBW infants are shown in Fig. 2. The birth place adjusted proportion of deaths among those who received FCHV follow up visit and those who did not receive were $2 \%$ (95\% CI: $1 \%$; $2 \%)$ and 11\% (95\% CI: 6\%; 18\%) respectively $(P<0.001)$. Further disaggregation of data showed the highest difference was observed for Dalits (27\% vs $1.1 \%)$ and Disadvantaged Non-Dalit Terai Caste ethnic groups $(27.0 \%$ vs $2.0 \%)$. The relative risk of death in LBW infants who received FCHV follow up visit was $84 \%$ less as compared to LBW infants who did not receive $(R R=0.16$; 95\% CI: 0.09, 0.29).

\section{Discussion}

The results demonstrated that community based management of low birth weight infants within an existing government health system of Nepal is effective in reducing risk of deaths in LBW infants. The study showed that the LBW newborns who received at least one follow up visit by FCHVs had lower risk of mortality at two months of age compared to those who received no follow up visits. It appears that MINI's home-based care by FCHVs which included a combination of weighing neonates within three days of birth, assessing neonates for danger signs, treating and referring sick neonates, encouraging exclusive breastfeeding, promoting skin-toskin contact, counseling on recognition of danger signs and prompt care seeking in the event of PSBI or LBI reduces mortality among LBW infants. It has been demonstrated in other studies that promoting immediate drying and wrapping of the baby, hygienic cord tying and cutting, skin-to-skin contact with the mother, and initiation of breastfeeding within the first hour of birth are critical for improving the survival of newborn infants, especially those who have a low birth weight [26].

Concerns raised about the home-based or community based management of newborns often point to the risks involved in treating critical infants in settings so far removed from tertiary health facilities. While the ideal scenario would allow mothers to easily access these types of facilities, the reality in rural and low-resource settings is that the distance, cost and access to such services is out of reach for most families. Given these circumstances, services such as those provided by FCHVs in Nepal are critical for bringing essential newborn care closer to the home where more than $60 \%$ of deliveries occur [6]. Findings from our analysis provide 
Table 1 Baseline characteristics of low birth weight infants

\begin{tabular}{|c|c|c|c|c|}
\hline Variables & $\begin{array}{l}\text { Total } \\
(n=2229)\end{array}$ & $\begin{array}{l}\text { Follow up visit } \\
(n=2108)\end{array}$ & $\begin{array}{l}\text { No Follow up visit } \\
(n=121)\end{array}$ & $P$-value \\
\hline \multicolumn{5}{|l|}{ Sex } \\
\hline Male & $1040(47 \%)$ & $975(46 \%)$ & $65(54 \%)$ & 0.095 \\
\hline Female & $1189(53 \%)$ & $1133(54 \%)$ & $56(46 \%)$ & \\
\hline \multicolumn{5}{|l|}{ Ethnicity } \\
\hline Upper Caste & $315(14 \%)$ & $298(14 \%)$ & $17(14 \%)$ & \\
\hline Disadvantaged Janajati & $959(40 \%)$ & $924(44 \%)$ & $52(43 \%)$ & \\
\hline Disadvantaged Non-Dalit Terai & $178(8 \%)$ & $167(8 \%)$ & $11(9 \%)$ & \\
\hline Dalit & $468(21 \%)$ & $449(21 \%)$ & $19(16 \%)$ & \\
\hline Religious Minority (Muslim) & $178(8 \%)$ & $165(8 \%)$ & $13(11 \%)$ & 0.481 \\
\hline Others & $114(5 \%)$ & $105(5 \%)$ & $9(7 \%)$ & \\
\hline \multicolumn{5}{|l|}{ Illness } \\
\hline Yes & $784(34 \%)$ & $746(35 \%)$ & $38(31 \%)$ & 0.372 \\
\hline No & $1445(66 \%)$ & $1362(65 \%)$ & $83(68 \%)$ & \\
\hline \multicolumn{5}{|l|}{ Birth Place } \\
\hline Home & $1742(71 \%)$ & $1657(79 \%)$ & $85(70 \%)$ & \\
\hline Health Facility & $487(29 \%)$ & $451(21 \%)$ & $36(30 \%)$ & 0.03 \\
\hline First place of treatment $(n=784)$ & 784 & 746 & 38 & \\
\hline Home & $194(25 \%)$ & $187(25 \%)$ & $7(18 \%)$ & \\
\hline Government Health Facility & $136(17 \%)$ & $128(17 \%)$ & $8(21 \%)$ & \\
\hline Private Health Facility & $49(6 \%)$ & $45(6 \%)$ & $14(11 \%)$ & \\
\hline Traditional Healers & $14(1 \%)$ & $13(2 \%)$ & $1(3 \%)$ & \\
\hline $\mathrm{FCHV}$ & $391(50 \%)$ & $373(50 \%)$ & $18(47 \%)$ & $0.590^{\mathrm{a}}$ \\
\hline
\end{tabular}

${ }^{\mathrm{a}}$ Fischer exact test

further indications that it may be possible to save newborn lives in resource-poor settings by implementing home-based newborn care delivered by community health workers, and by promoting perinatal care at grass root level health facilities [27]. Another important finding of our study is that even the most deprived ethnic groups such as Dalit and non-Dalit Terai Caste Groups had a much lower mortality if they had received at least one follow visit. This is an important finding also from a program-implementation perspective because Dalits and Terai Madhesi groups continue to experience higher relative levels of neonatal mortality [28].

The integration of essential newborn care practices such as newborn weighing and follow-up visits are an important component for reducing young infant mortality. In the implementation process, it was observed that in addition to early antenatal contact through existing government health programs, weighing the newborn was

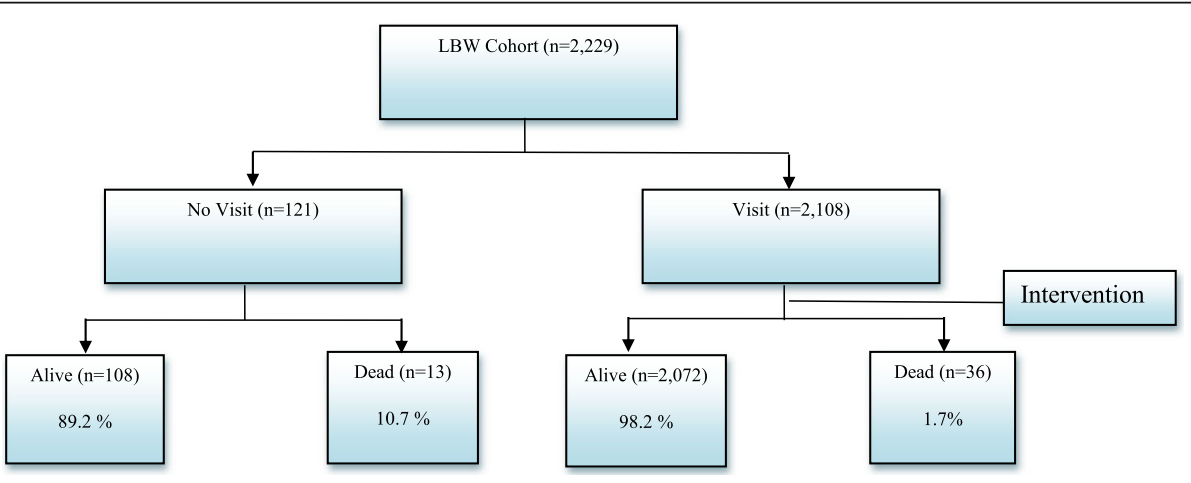

Fig. 2 Mortality status at two months in LBW infants 
an important entry point for identifying danger signs in infants. Mothers notified birth to FCHVs when they were aware that part of the first postnatal care visit would involve weighing of the newborn. By identifying births early and providing extra visits for LBWs, there was also an increased opportunity to identify PSBI cases in the home. This identification is critical for intervening through early treatment since neonatal sepsis often progresses rapidly and has a very high mortality [29].

There are several limitations to the current study. As the program was implemented in all VDCs of Morang district with no control group, the internal comparison between receiving at least one visit and no visit may not be representative to the population of infants who could benefit from this study. The visit by an FCHV may not be the sole factor contributing to a reduction in mortality in neonates. We do not have documented information on why the non-exposed did not get follow up-visits. However, the opportunities for receiving care by FCHVs for those who received care and those who did not receive care was comparable because FCHVs were distributed homogeneously in their community. The date of the follow-up visits is not available as the FCHVs just circled the number of the visit. Furthermore, limited data collection restricted conclusions on whether or not visits had a direct impact on increased weight at the end of the two-month period since young infants were not reweighed after they were identified as LBWs.

Because of the observational nature of this study, data on reasons for no follow up visits are unavailable. However, we can speculate that no follow-up visit may be related to geographical obstacles and long distances which prevented FCHVs from frequently visiting clients, cultural elements such as postpartum practices that lead a new mother to move from her in-laws' home to her paternal home, and/or mothers' education and awareness of LBW as a neonatal health issue [30].

Despite uncertainties related to the characteristics of both those receiving care and providing care for LBWs, MINI showed that LBW infants who received an FCHV visit experienced a significantly reduced risk of death compared to those who did not. The current study suggests that, to save the life of LBW infants simple home-based measures implemented through trained health volunteers within the existing government health system is effective when technically more sophisticated measures such as tertiary health centers, pediatricians, and expensive technology are scarce.

\section{Conclusions}

Findings from the community based management and treatment of illness of newborns showed that there was lower risk of death among LBW infants who received home-based care from FCHVs. This indicates that home-based newborn care by trained health volunteers might have a significant impact in reducing young infant mortality in resource poor settings such as Nepal.

\section{Abbreviations \\ DPHO: District Public Health Office; FCHV: female community health volunteers; LBW: low birth weight; MDG: millennium development goal; MINI: Morang innovative neonatal intervention; PSBI: possible severe bacterial infections; RR: relative risk; USD: United States Dollar; VDC: Village \\ Development Committee; WIRB: Western Institutional Review Board \\ Acknowledgement \\ The authors would like to thank the staff of the Morang District Public Health Office and the JSI/MINI team and the staff of JSI/Nepal Family Health Program which provided logistical support to MINI. Sincere thanks to the Saving Newborn Lives project, implemented by Save the Children/Nepal and to USAID for financial support for the implementation of the overall MINI program. Special thanks are extended to Female Community Health Volunteers who worked tirelessly for the project.}

\section{Funding}

Saving Newborn Lives/Save the Children-USA to the JSI Research and Training Institute, Inc. Additional support was provided by the United States Agency for International Development, Nepal, through the Nepal Family Health Program/JSI R\&T. The funding bodies have no role in data collection, research, and the findings and views expressed in this manuscript.

Availability of data and materials

The data of the study is available on the request to the authors.

\section{Authors' contributions}

$\mathrm{DN}, \mathrm{PD}, \mathrm{RH}, \mathrm{JS}, \mathrm{GK}$ and $\mathrm{CL}$ set conception and design of the study. DN analyzed the data. DN, GK, PD, JS and CL made the first draft of the manuscript. PD, RH, JS, LD, VK, SRM and PK reviewed the manuscript and revised critical points with DN. All authors read and approved the final manuscript.

\section{Competing interests}

The authors declare that they have no conpeting interests.

Consent for publication

Not applicable.

Ethics approval and consent to participate

The paper has obtained ethics approval from designed body in Nepal, and all the participants has been consented verbally before participation in the study. Verbal consent was taken because it would not adversely affect the rights and welfare of the participants. Whenever appropriate, the caregivers were provided with additional pertinent information.

\section{Publisher's Note}

Springer Nature remains neutral with regard to jurisdictional claims in published maps and institutional affiliations.

\section{Author details}

${ }^{1}$ Center for Global Health, Department of Public Health, Aarhus University, Aarhus, Denmark. ${ }^{2} \mathrm{JSI}$ Research and Training Institute Inc, Kathmandu, Nepal. ${ }^{3}$ Nepal Development Society, Chitwan, Nepal.

Received: 29 September 2015 Accepted: 26 May 2017

Published online: 11 July 2017

\section{References}

1. World Health Organization: International statistical classification of diseases and related health problems. In., 10 revision edn. Geneva: World Health Organization; 1992. 
2. Wardlaw T, Blanc A, Zupan Z, Åhman E. Low birthweight : country, regional and global estimates. In: United Nations Children's fund and World Health Organization; 2004.

3. Lawn JE, Cousens S, Zupan J. 4 million neonatal deaths: when? Where? Why? Lancet. 2005;365(9462):891-900.

4. Save the Children. State of the World's newborns. Washington DC: Save the children; 2001

5. United Nations Millennium Declaration. United Nations general assembly resolution 55/2. New York: United Nations; 2000

6. Ministry of Health and Population (MoHP) [Nepal], New ERA, ICF International Inc.: Nepal Demographic and Health Survey. In. Kathmandu: Nepal: Ministry of Health and Population, New ERA, and ICF International, Calverton, Maryland; 2012.

7. Ministry of Health and Population (MOHP) [Nepal], New ERA, Macro International Inc: Nepal Demographic and health survey 2006. In. Kathmandu, Nepal: Ministry of Health and Population, New ERA, Mactro International Inc.; 2007

8. Kramer MS. The epidemiology of adverse pregnancy outcomes: an overview. J Nutr. 2003;5(Suppl 2):1592S-6S.

9. Aleman J, Brännström I, Liljestrand J, Peña R, Persson LA, Steidinger J. Saving more neonates in hospital: an intervention towards a sustainable reduction in neonatal mortality in a Nicaraguan hospital. Trop Dr. 1998; 28(2):88-92.

10. Duke T, Willie L, Mgone JM. The effect of introduction of minimal standards of neonatal care on in-hospital mortality. P N G med J. 2000:43(1-2):127-36.

11. Conde-Agudelo A, Belizán JM, Diaz-Rossello J. Kangaroo mother care to reduce morbidity and mortality in low birthweight infants. Cochrane Database Syst rev. 2011;16(3):1-23.

12. Bang AT, Baitule SB, Reddy HM, Deshmukh MD, Bang RA. Low birth weight and preterm neonates: can they be managed at home by mother and a trained village health worker? J Perinatol. 2005;(Suppl 1):S72-81.

13. Pratinidhi A, Shah U, Shrotri A, Bodhani N. Risk-approach strategy in neonatal care. Bull World Health Organ. 1986;64(2):291-7.

14. WHO, Unicef: Handbook IMCI Itegrated Management of Childhood IIness. In. Geneva: WHO; 2005

15. New ERA: An analytical report on national survey of female community health volunteers of Nepal. In. Kathmandu; 2006.

16. Population Reference Bureau: World population data sheet. In: The world at 7 billion. Washington; 2011.

17. Central Bureau of Statistics: National population and housing census 2011(National Report). In. Edited by National Planning Commission Secretariat, vol. 1. Kathmandu: Government of Nepal.; 2012: 1.

18. White RC. Global case studies in maternal and chld health. Jones and Bartlett Learning: Massachusetts; 2012.

19. Khanal S, Sharma J, VS GC, Dawson P, Houston R, Khadka N, et al. Community health workers can identify and manage possible infections in neonates and young infants: MINI-a model from Nepal. J Health Popul Nutr. 2011:29(3):255-64.

20. Integrated Center for Mountain Development, Central Bureau of Statistics, Netherland Development Organization: Districts of Nepal: Indicator of Development. In. Kathmandu; 2003

21. UNDP: Nepal human development report: empowerment and poverty reduction 2004. 2005.

22. Bang AT, Bang RA, Reddy MH, Baitule SB, Desmukh MD, Paul VK, et al. Simple clinical criteria to identify sepsis or pneumonia in neonates in the community needing treatment or referral. Pediatr Infect Dis J. 2005;24(4):335-41.

23. Weber MW, Carlin JB, Gatchalian S, Lehmann D, Muhe L, Mulholland EK, et al., WHO Young Infants Study Group. Predictors of neonatal sepsis in developing countries. Pediatr Infect Dis J. 2003;22(8):711-7.

24. Bang AT, Bang RA, Baitule SB, Reddy MH, Deshmukh MD. Effect of homebased neonatal care and management of sepsis on neonatal mortality: field trial in rural India. Lancet. 1999;354(9194):1955-61.

25. Health Management Information System (HMIS): Ethnic Grouping. In. Edited by Department of Health Services. Kathmandu: Ministry of Health and Population; 2010.

26. Iyengar SD, lyengar K, Martines JC, Dashora K, Deora K. Childbirth practices in rural Rajasthan, India: implications for neonatal health and survival. J Perinatol. 2008;28:S23-s30.

27. Paul VK, Singh M. Regionalized perinatal care in developing countries. Semin Neonatal. 2004;9(2):117-24.
28. Nguyen K-H, Jimenez-Soto E, Morgan A, Morgan C, Hodge A. How does progress towards the MDG 4 affect inequalities between different subpopulations? Evidence from Nepal. J Epidemiol Community Health. 2013:67:311-9.

29. Remington JS, Klein JO. Infectious diseases of the fetus and newborn infant. Philadelphia, PA: WB Saunders; 1990.

30. Morrison J, Osrin D, Shrestha B, Tumbahangphe KM, Tamang S, Shrestha D: How did formative research inform the devleopment of a women's group intervention in rural Nepal? J Perinatol 2008, 28(S14-S22).

\section{Submit your next manuscript to BioMed Central and we will help you at every step:}

- We accept pre-submission inquiries

- Our selector tool helps you to find the most relevant journal

- We provide round the clock customer support

- Convenient online submission

- Thorough peer review

- Inclusion in PubMed and all major indexing services

- Maximum visibility for your research

Submit your manuscript at www.biomedcentral.com/submit
) Biomed Central 